\title{
Proposal of two visual tree risk assessment methods for urban parks in Montevideo, Uruguay
}

\author{
Propuesta de dos métodos de evaluación visual del riesgo de árboles \\ para parques urbanos en Montevideo, Uruguay
}

\author{
Ana Paula Coelho-Duarte a, Gustavo Daniluk-Mosquera a, Virginia Gravina ${ }^{\text {b, }}$ \\ Andrés Hirigoyen ${ }^{\mathrm{c}}$, Óscar Vallejos-Barra ${ }^{\mathrm{d}}$, Mauricio Ponce-Donoso $\mathrm{d} *$ \\ a Universidad de la República, Facultad de Agronomía, Departamento de Producción Forestal y Tecnología de la Madera, \\ Avda. Garzón 780, 12900 Montevideo, Uruguay, paula.coelho@fagro.edu.uy, gdaniluk@fagro.edu.uy

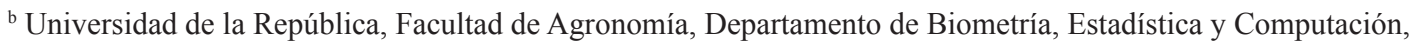 \\ Avda. Garzón 780, 12900 Montevideo, Uruguay, virginia@fagro.edu.uy \\ c Instituto Nacional de Investigación Agropecuaria, Programa Nacional de Investigación en Producción Forestal, \\ Ruta 5 km 386, Tacuarembó, Uruguay, andreshirigoyen@gmail.com \\ *Corresponding Author: ${ }^{d}$ Universidad de Talca, Escuela de Ingeniería Forestal, Avda. Lircay s/n, Talca, Chile, \\ tel.: 56-71-2200432, ovallejo@utalca.cl,mponce@utalca.cl
}

\begin{abstract}
SUMMARY
The risk assessment of urban trees is a challenge that must be addressed by many cities, in consideration of their climatology, management and spatial heterogeneity. Since these trees are in stages of aging, added to bad practices, inadequate selection and establishment, amongst others, their early elimination, and hence the loss of the ecosystem services they provide, is being promoted. For this reason, two tree risk assessment methods were developed to be applied in a complementary manner in urban parks, one basic visual (BV) and the other detailed visual (DV), both structured with the components of likelihood of failure, likelihood of impact, consequence and risk rating, being analyzed qualitatively and semi quantitatively. The methods were applied in 24 trees of Eucalyptus and Tipuana genus by two groups of assessors, experienced and inexperienced, totaling 192 assessments. Results were analyzed with a linear mixed model (LMM), which showed differences between both methods for the likelihood of failure, where the assessment of branches turned out to be the attribute with the highest impact. The methods proved to be suitable to be used in a complementary manner, since BV turns out to be efficient when it is necessary to assess a large number of trees. DV turned out to be more effective, since it was able to identify more precisely the attributes of the tree that must be considered for adequate risk mitigation and management. Therefore, their combined use is recommended for risk assessment in trees established in parks.
\end{abstract}

Key words: arboriculture, urban trees, hazard tree, tree risk rating, linear mixed model.

\section{RESUMEN}

La evaluación del riesgo de los árboles urbanos es un desafío que numerosas ciudades deben abordar, en consideración a su climatología, gestión y heterogeneidad espacial, debido al hecho que el arbolado se encuentra en etapas de envejecimiento, sumado a malas praxis, inadecuada selección y establecimiento, entre otras, que están propiciando su eliminación temprana y, por ende, la pérdida de los servicios ecosistémicos que proveen. Por ello se desarrollaron dos métodos de evaluación del riesgo de árboles para ser aplicados complementariamente en parques urbanos, uno visual básico (VB) y otro visual detallado (VD), estructurados con las componentes de probabilidad de falla, probabilidad de impacto, consecuencia y clasificación de riesgo, siendo analizados cualitativa y cuantitativamente. Los métodos fueron aplicados en 24 árboles de los géneros Eucalyptus y Tipuana por dos grupos de evaluadores, con experiencia y sin experiencia, totalizando 192 evaluaciones. Los resultados se analizaron con un modelo lineal mixto (MLMiX), que mostró diferencias entre ambos métodos para la probabilidad de falla, donde la valoración de las ramas secundarias resultaron ser el atributo de mayor impacto. Los métodos demostraron ser adecuados para ser usados complementariamente, ya que el VB resulta ser eficaz cuando se requiere evaluar gran cantidad de árboles, mientras que el VD resultó ser más efectivo, pues fue capaz de identificar de forma más precisa los atributos del árbol que deben ser considerados para una adecuada mitigación y gestión del riesgo. Por lo anterior, se recomienda su uso combinado para la evaluación del riesgo en árboles establecidos en parques.

Palabras clave: arboricultura, árboles urbanos, árbol peligroso, clasificación del riesgo de los árboles, modelo lineal mixto. 


\section{INTRODUCTION}

Trees fulfill various environmental functions besides beautifying the city, such as capturing carbon from carbon dioxide emissions, reducing electricity consumption by cooling or heating buildings, mitigating suspended particles, amongst other functions that help provide well-being to the population (Miller et al. 2015, Ponce-Donoso et al. 2016). Likewise, their presence in the city has both intrinsic and monetary value (Ponce-Donoso et al. 2012), which gives cities heritage value, both public and private.

The provision of these benefits is maintained if trees are in good sanitary conditions and adapted to the site, otherwise, they can cause damage to people or property, or temporary cut of essential services due to failures of branches or entire trees (Calaza and Iglesias 2016).

Montevideo has more than 200.000 street trees, to which are added those located in squares, parks and private locations (Terrani 2014), where most predominant species are classified as "mature functional" or "mature in late functional stages". Terrani (2014) indicates that the vegetative state of trees in general is good, though there are a significant number of trees of advanced age and large size, relevant characteristics at the time of carrying out a risk assessment (Dunster et al. 2017, Koeser and Smiley 2017).

In this context, the assessment of the risk condition of the urban tree is relevant for society, mainly for municipal managers, posing two important challenges: the determination of risk and its management (Calaza and Iglesias 2016), reducing its potentiality and preserving a desirable vegetation cover.

For the risk assessment of urban trees, several methods have been proposed, highlighting those that use visual assessment, the best known and widespread amongst urban arboricultural specialists being the "Tree Hazard Evaluation Method" (Matheny and Clark 1994), "A Guide to Identifying, Assessing, and Managing Hazard Trees in Developed Recreational Sites of the Northern Rocky Mountains and the Intermountain West" (Guyon et al. 2017), "Quantified Tree Risk Assessment" (Ellison 2018), "Tree Hazard: Risk Evaluation and Treatment System" (ForbesLaird 2010) and "Best Management Practice - Tree Risk Assessment" (Dunster et al. 2017).

Although there are methodologies at an international level, none have been validated or adapted to places other than those where they have been developed, hence the reliability of their application and results cannot be guaranteed (Koeser et al. 2016). However, they are useful as a point of comparison for developing a new method or a new version that is suitable.

The American National Standards Institute (ANSI 2011) Standard A300, specifically Part 9 on tree risk assessment, provides guidelines for this practice and proposes standards for issuing specifications. According to this standard, the methods can be divided into three levels of applicability: Level 1 - Limited Visual, where the as- sessment can be applied from a car in motion; Level 2 Basic Visual, its use being supported by a form and simple tools, such as a rubber hammer and binoculars, amongst others; and Level 3 - Advanced Assessment, where the use of advanced equipment, such as a sonic tomography, micro drill or ground penetrating radar, is suggested to detect decay and remaining resistance.

In accordance with the above, the assessment Level 1, despite being limited, is usually used to identify the most obvious defects of the tree, being a good tool to assess a large population of trees (Rooney et al. 2005), responding to the principle of efficiency that should be part of municipal actions.

Regarding the assessment Level 2, there are different methods, where each proposal seeks to give an approach that best fits the needs of the context where it is applied (Calaza and Iglesias 2016, Reyes et al. 2018, CoelhoDuarte et al. 2021).

When investigating 15 urban tree risk assessment methods, Norris (2010) proposes that methods should provide accurate, reliable and verifiable results, and data should be collected in an easy, simple and economically viable way. His hypothesis is that different assessors would have similar results, which would help in identifying the differences produced by each method. Given the existence of significant differences, the author concludes that the variation is influenced by the final result of each method. Additionally, the performance of the different components that make up the method should be considered as contributing to these differences (Coelho-Duarte et al. 2021).

On the other hand, the levels of uncertainty associated with the methods may be related to various factors, such as the experience and knowledge of the assessor regarding the characteristics of the evaluated species. In some cases, defects are highly visible, such as cracks or the presence of fungi fruiting bodies, though most of them are not easily identifiable and assumptions must often be made. Calaza and Iglesias (2016) point out that a good assessor can analyze the wood condition through changes in color and texture, although detecting them in the initial stages is a difficult task. To reduce the uncertainty of assessments, the use of complementary instruments is recommended, these help in the identification of defects and the measurement of the remaining resistance of the tree (Wessolly and Erb 2016). However, the use and interpretation of this instruments are not easy (Calaza and Iglesias 2016), being a potential inconvenience, as experience remains a relevant issue when assessing risk.

Koeser et al. (2017) review the likelihood of failure considering the ANSI A300 Standard (ANSI 2011), where assessments made by various assessors and different assessment levels are compared. The authors find that classification means are lower for the limited visual assessment method than for the basic and advanced visual methods, while the difference between the latter is less pronounced. There are very few studies in Latin America with the eva- 
luation of the adherence, adaptation or development of a method applicable to a particular condition (be it territorial or managerial) as objectives. Some are aimed at proposing context-specific methodologies (Sampaio et al. 2010, Conceição et al. 2017), while others compare existing methods and propose their adjustment (Reyes et al. 2018, Ivasko et al. 2019), without consistent results to recommend a specific method.

In this work, two methods are proposed for the visual risk assessment of urban trees in parks. These methods differ in the level of detail of the information collected and analyzed in the field and should be applicable complementary under the principles of effectiveness and efficiency, within a protocol established in tree risk management at municipal level. The hypotheses that led this study are the following: i) as the level of detail of the assessment increases, there is a change in the risk valuation; ii) the genus and type of assessors affect assessments; iii) qualitative and semi-quantitative risk classifications behave differently regarding distribution. In addition, the effect of each risk assessment component and their respective attributes on the final risk classification is identified.

\section{METHODS}

Formulation of new proposals. Two new proposals were formulated: (a) basic visual (BV) assessment, where simple tools are used, which allows trees to be inventoried, and can be applied both at technical and professional level; and (b) detailed visual (DV) assessment, that can be complemented with the use of non-destructive equipment and requiring advanced training for application. This last method is intended, preferably, for the assessment of trees presenting high to extreme risk, with heritage / monumental nature, or that present some type of conservation conflict (table 1). Methods were developed based on several methods available in literature (Matheny and Clark 1994, Forbes-Laird 2010, Dunster et al. 2017, Guyon et al. 2017, Ellison 2018).

Table 1. Characteristics of the methods.

Características de los componentes.

\begin{tabular}{lll}
\hline Method & Basic Visual Assessment (BV) & Detailed Visual Assessment (DV) \\
\hline & $\begin{array}{l}\text { Seven categories of structural defects (Pokorny } \\
\text { 2003): decay, cracks, root problems, weak unions, } \\
\text { canker, poor architecture, dead wood. }\end{array}$ & $\begin{array}{l}\text { Tree's part defects: root collar, trunk, scaffold and } \\
\text { lateral branches, roots. }\end{array}$ \\
Likelihood of Failure & $\begin{array}{l}\text { Likelihood of Failure divided in four levels (adapt- } \\
\text { ed from Pokorny 2003): low (1), moderate (2), } \\
\text { high (3), extreme (4). }\end{array}$ & $\begin{array}{l}\text { Likelihood of Failure divided in four levels for } \\
\text { each tree's part (adapted from Dunster et al. }\end{array}$ \\
& $\begin{array}{l}\text { 2017): improbable (1), possible (2), probable (3), } \\
\text { imminent (4). }\end{array}$ \\
\hline
\end{tabular}

Type of target: pedestrians / cyclists, vehicle, structures / services, others.

Occupation rate: rare, occasional, frequent, constant / structures.

Likelihood of Impact Target zone and target protection.

Likelihood of Impact divided in four levels (adapted from Dunster et al. 2017): very low (1), low (2), Medium (3), High (4).

Tree part most likely to fail.

Examples, part size and weight for each level.

Consequence divided in four levels (adapted from

Consequences $\quad$ Forbes-Laird 2010): insignificant (1), minor (2), significative (3), severe (4).

Fall distance.

Reduced mass.

Dendrometric measurements.

Site factors.

Recommended control measures.
Tree part most likely to fail.

Qualitative ranks with examples for each type of target.

Consequence divided in four levels (adapted from Dunster et al. 2017): insignificant (1), minor (2), significant (3) and severe (4).

Fall distance.

Non-destructive equipment to be used.

Advanced dendrometric measurements.

Site and root zone characteristics.

Climatic conditions.

Raimbault's development stages. 
In $\mathrm{BV}$, the probability of general failure is evaluated, while in DV the likelihoods of failure are evaluated for each part of the tree: root collar, trunk, scaffold and lateral branches and root. For the analysis of the likelihood of failure component and subsequent analysis of risk in DV, the highest valuation found of the five evaluated parts was used.

Study area. The field work was carried out in Parque José Batlle y Ordóñez (Parque Batlle), one of the main green areas of Montevideo, Uruguay $\left(34^{\circ} 53^{\prime} 45^{\prime \prime} \mathrm{S}\right.$ and $56^{\circ}$ $\left.9^{\prime} 33^{\prime \prime} \mathrm{W}\right)$. This urban park is structured by different types of vehicular streets, uses and occupations, covering an area of 52.05 ha that includes sport infrastructure, cultural facilities, commercial and recreational areas, where hospitals, schools, and monuments are also located. The city is located at $136 \mathrm{~m}$ a.s.l. and has a population of 1.38 million inhabitants, representing almost $50 \%$ of the total population of the country. It has a humid subtropical Köppen-Geiger climate (Cfa), with average annual temperature of $16.7^{\circ} \mathrm{C}$ and annual rainfall of $1,100 \mathrm{~mm}$; Winter is humid, windy and cloudy, with the occurrence of storms; while summer is hot and humid, with little wind (INUMET 2020).

Application of the new methods. 24 trees were selected, 12 of Eucalyptus L'Hér. genus and 12 from Tipuana (Benth.) Benth. genus, located in different parts of the Parque Batlle, prevailing those in areas with a larger presence of vehicles and pedestrians, although some of the eucalyptus trees were in areas inside the park, with occasional to intermittent use. The selection considered different situations of likelihood of failure, impact and consequence, incorporating trees at all possible levels of risk.

Evaluations were carried out in the fall of 2019 before the defoliation of Tipuana trees, by volunteers separated into two groups: one made up of two professionals with experience in risk assessments, called Senior-Level group (SL), and the other by two agricultural science advanced students with no experience in risk assessment and basic knowledge of urban trees, called Junior-Level group (JL).

Risk rating analyses. To analyze the risk, two different ways were chosen: a qualitative one, based on the matrix system of the ISA BMP method (Dunster et al. 2017), and a semiquantitative one, based on the simple addition of the components of likelihood of failure, likelihood of impact and consequence. The semiquantitative ranking was divided into four ranges (table 2), adapted from Guyon et al. (2017), allowing the complementary use of the risk management tool "As Low as Reasonably Practicable" ALARP - (Ellison 2018). Subsequently, the 192 evaluations of qualitative and semi-quantitative risk ratings were compared and graphed.

Statistical analysis. To identify differences between BV and DV methods, the components likelihood of failure,
Table 2. Risk rating per type of analysis.

Clasificación del riesgo por tipo de análisis.

\begin{tabular}{ccc}
\hline $\begin{array}{c}\text { Qualitative Risk } \\
\text { Rating }\end{array}$ & $\begin{array}{c}\text { Semiquantitative Risk } \\
\text { Rating }\end{array}$ & Index $^{\text {a }}$ \\
\hline Low & 3 to 8 & 1 \\
Moderate & 9 & 2 \\
High & 10 and 11 & 3 \\
Extreme & 12 & 4 \\
\hline
\end{tabular}

${ }^{a}$ Standardized Risk Rating

likelihood of impact and consequence were considered. A total of 192 assessments were counted. The differences among methods, genus, type of assessors and the interactions between them were tested using analysis of variance (ANOVA) at a level $P<0.01$. The ANOVA used was a linear mixed model (LMM), considering the "tree" effect as a random factor, since all methods were applied to the same trees. When the null hypothesis was rejected, means were compared using Fisher's Least Significant Difference (LSD) test $(\alpha=0.01)$. When significant differences were identified for a certain component between the visual assessment methods proposed, their valuations were analyzed separately in each method.

In turn, an ANOVA and means comparison tests were applied to analyze the attributes of likelihood of failure of BV (general likelihood of failure) and DV (likelihood of failure by tree part) methods. Regarding the DV method, to determine which assessments of the tree part had a significant effect on the index of the likelihood of failure component (table 1), an LMM was constructed, where the response variable was the index of likelihood of failure and the independent variables were the likelihoods of failure for each part.

The results of the final risk rating from the semiquantitative and qualitative analyses were also analyzed with LMM $(P<0.01)$, considering the method, type of assessor and genus as fixed effects, and as a random effect, the tree.

To evaluate the effect of the components on the risk rating, an LMM was constructed for each proposed method, where the response variable was the standardized indices of risk rating (table 2) and the independent variables were the indices of each component (table 1).

The data was analyzed with the lmer function of the $\mathrm{R}$ lme4 library, interconnected to the InfoStat version 2020 software (Di Rienzo et al. 2020). SigmaPlot version 12 was used to build the graphs.

\section{RESULTS}

Results per component. The methods presented significant interaction between type of assessor and genus for the likelihood of failure, where the JL group valued Eucalyptus in 
higher ranges than Tipuana (figure 1A), not observing significant differences for these factors. Regarding methods, there were significant differences, where the DV method presented higher mean and median (figure 1B).

The BV method separately presented the same result as the analysis of the entire data (figure 1C). In the case of the DV method, there were no significant differences between genus and type of assessors, nor interaction between them.

No significant differences were found between $\mathrm{BV}$ and DV methods for the likelihood of impact and consequence components. Overall, significant differences were found between the type of assessors for the likelihood of impact (figure 1D), while separately there were no significant differences between the type of assessors and genus for any of the methods. For the consequence there were no significant differences between type of assessors and genus when the data was analyzed both as a whole and separately for each method.

Analysis of the likelihood of failure. For the attributes that define the likelihood of failure, both for BV and DV, no significant differences were found between type of assessors and genus, nor significant interaction between each attribute with these factors; while significant differences were found between the attributes that define this component (figure 2).

In the DV method, the assessment of the branches was the only attribute that had a significant effect $(\alpha=0.01)$ for
(A)

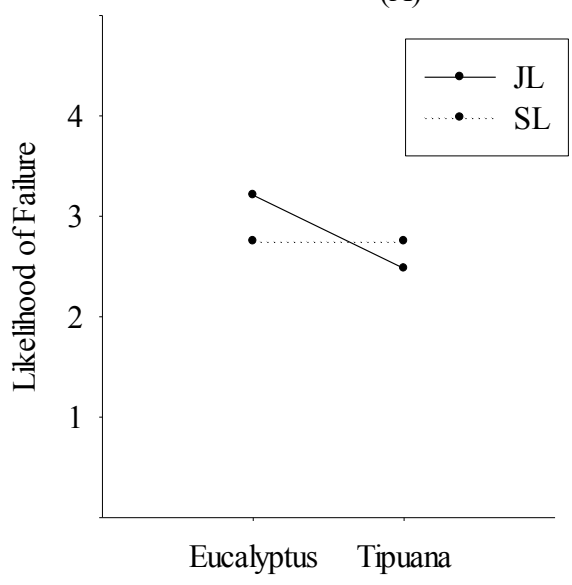

(C)

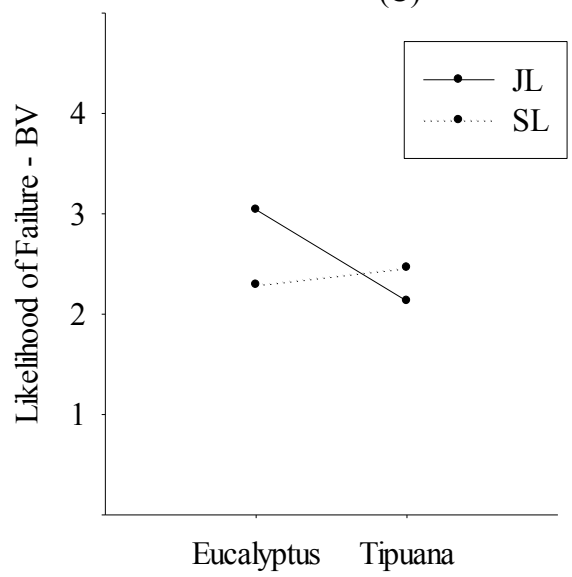

(B)

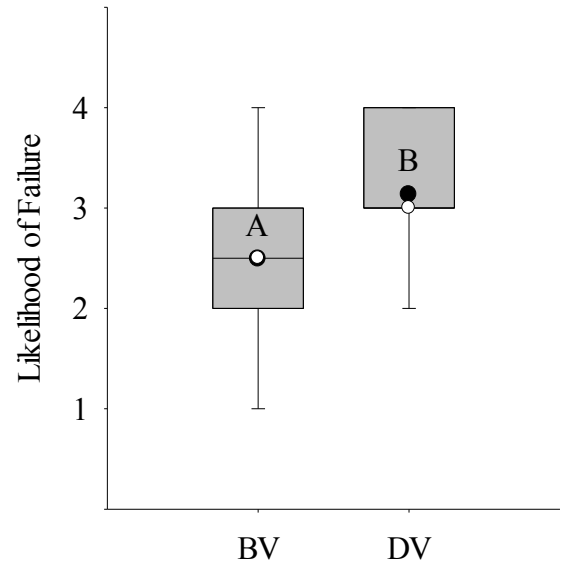

(D)

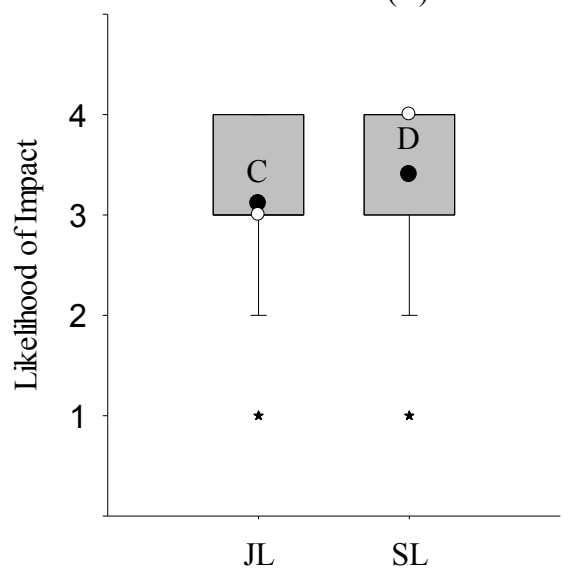

Figure 1. Component results $(P<0.01)$. (A) Interaction graphic type of assessor $\mathrm{x}$ genus for both methods. (B) Boxplot (bars) for likelihood of failure for both methods. (C) Interaction graphic type of assessor x genus for BV method. (D) Boxplot (bars) for likelihood of impact for type of assessor. Mean adjusted (black points), medians (white circles) and outliers (black stars). Dissimilar letters denote statistically significant differences in mean ratings as determined with an LSD Fisher test $(\alpha=0.01)$.

Resultados de los componentes $(P<0,01)$. (A) Gráfico de interacción tipo de evaluador $\mathrm{x}$ género para ambos métodos. (B) Diagrama de caja (barras) para la probabilidad de falla para ambos métodos. (C) Gráfico de interacción tipo de evaluador x género para el método VB. (D) Diagrama de caja (barras) para la probabilidad de impacto por tipo de evaluador. Media ajustada (puntos negros), medianas (círculos blancos) y valores atípicos (estrellas negras). Las letras diferentes denotan diferencias estadísticamente significativas en las medias determinadas con una prueba de LSD Fisher $(\alpha=0,01)$ 
both genera. There was no level 1 (improbable) for this attribute and neither for the component likelihood of failure in the DV method. As expected, when the assessment of the likelihood of failure of branches increased, the index of the component likelihood of failure also rose.
Analysis of risk rating. There were no significant differences for the factors analyzed, or interaction between them in the qualitative analysis $(\alpha=0.01)$. In the semiquantitative analysis, there were significant differences between BV and DV methods (figure 3A); while there were no signifi-

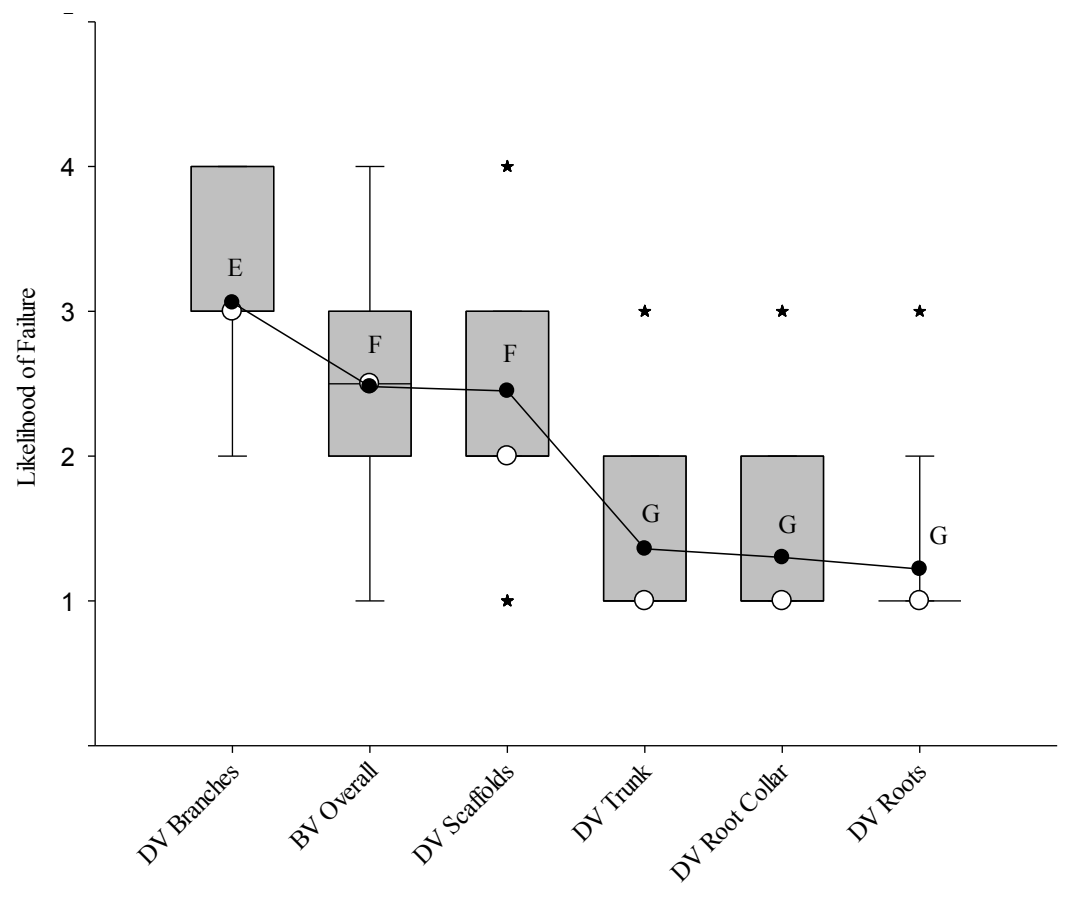

Figure 2. Boxplot (bars) for likelihood of failure ratings for BV and DV by attribute. Mean adjusted (black points), medians (white circles) and outliers (black stars). Dissimilar letters denote statistically significant differences in mean ratings as determined with an LSD Fisher test $(\alpha=0.01)$.

Diagrama de caja (barras) para la probabilidad de falla de VB y VD por atributo. Media ajustada (puntos negros), medianas (círculos blancos) y valores atípicos (estrellas negras). Las letras diferentes denotan diferencias estadísticamente significativas en las medias determinadas con una prueba de LSD Fisher $(\alpha=0,01)$.
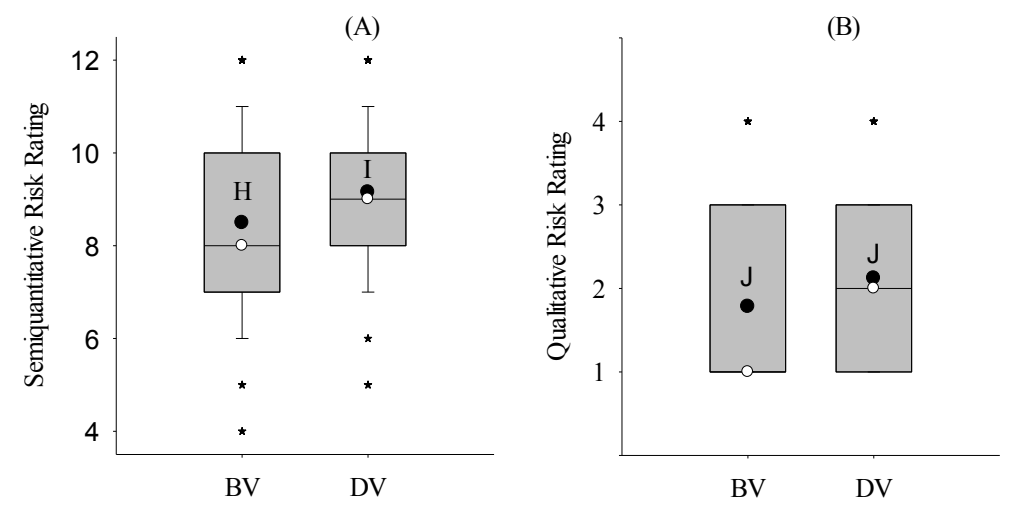

Figure 3. Boxplot (bars) for (A) semiquantitative risk rating and (B) qualitative risk rating for both methods. Mean adjusted (black points), medians (white circles) and outliers (black stars). Dissimilar letters denote statistically significant differences in mean ratings as determined with an LSD Fisher test $(\alpha=0.01)$.

Diagrama de caja (barras) para (A) clasificación del riesgo semicuantitativa y (B) clasificación de riesgo cualitativa para ambos métodos. Media ajustada (puntos negros), medianas (círculos blancos) y valores atípicos (estrellas negras). Las letras diferentes denotan diferencias estadísticamente significativas en las medias determinadas con una prueba de LSD Fisher $(\alpha=0,01)$. 
cant differences between type of assessors and genus, nor interaction between factors.

When the risk ratings were compared with the two forms of analyses for the same assessment (figure 4), risk rating 9 was obtained in both "low" and "moderate" levels; the same was true for risk rating 10, which was obtained in "moderate" and "high" levels.

In both methods, all the components had a significant effect on the final risk rating, with the likelihood of failure having the highest influence (figure 5).

\section{DISCUSSION}

When analyzing the methods together by component, the result indicates that, by increasing the level of detail of the visual assessment, the likelihood of failure tends to increase more (figure 1B), while this does not occur with the other components. Considering the methodological differences, this result was similar to that found by Koeser et al. (2017), where they point out that, when moving from a limited visual assessment to a basic visual one, that is, when the level of detail of assessment increases, there is a significant change in the likelihood of failure. Likewise, the higher level of detail of assessment reduced the effect of the type of assessors and genus factors, a different aspect from that reported by Koeser et al. (2017), where they indicate that no level of evaluation consistently reduces the variability between assessors, which could be due to the difference in the number of assessors considered in both studies.

No significant differences were found between BV and DV methods for the likelihood of impact and consequence because the attributes related to these components refer more to the characteristics of the place surrounding trees, such as the occupancy rate and the type of target, than to the characteristics of the tree itself. The likelihood of impact in both methods uses the same attributes for its assessment; While for the consequence, attributes are different (table 1), and as no differences were found between the type of assessors, it can be noted that the levels and descriptors of both methodologies are repeatable (Norris 2010).

When deepening the analysis of the likelihood of failure component for BV and DV methods, it was found that the branches were the attribute with the highest mean value (figure 2). It was observed that the mean of the valuation of the general likelihood of failure of the BV method was similar to the mean of the valuation of the scaffold of the DV method (figure 2). However, the general likelihood of failure showed a wide distribution, including all levels considered in the attributes of each part of the tree used in the DV method. This is due to the fact that the BV method makes a single general analysis of the tree to determine this likelihood, the result of which makes it a good approximation for the evaluation of this component at a basic level of detail, since it allowed the assessors to identify the four levels of likelihood of failure, according to the proposed methodology.

The assessment of branches in both genera was the only attribute that had a significant effect on the likelihood of failure component of the DV method. This result would indicate that the evaluation of this part of the tree has an important influence on the valuation for this level of visual assessment (DV) and therefore on the final risk rating, despite the fact that the consequence of the failure and impact of a branch is generally reduced due to its size (ForbesLaird 2010, Dunster et al. 2017, Ellison 2018).

The risk ratings of methods presented different behaviors when analyzed qualitatively and semi quantitatively (figure $3 \mathrm{~A}$ and $3 \mathrm{~B}$ ). In the semiquantitative analysis, the proposed ranges (table 2) would indicate that when

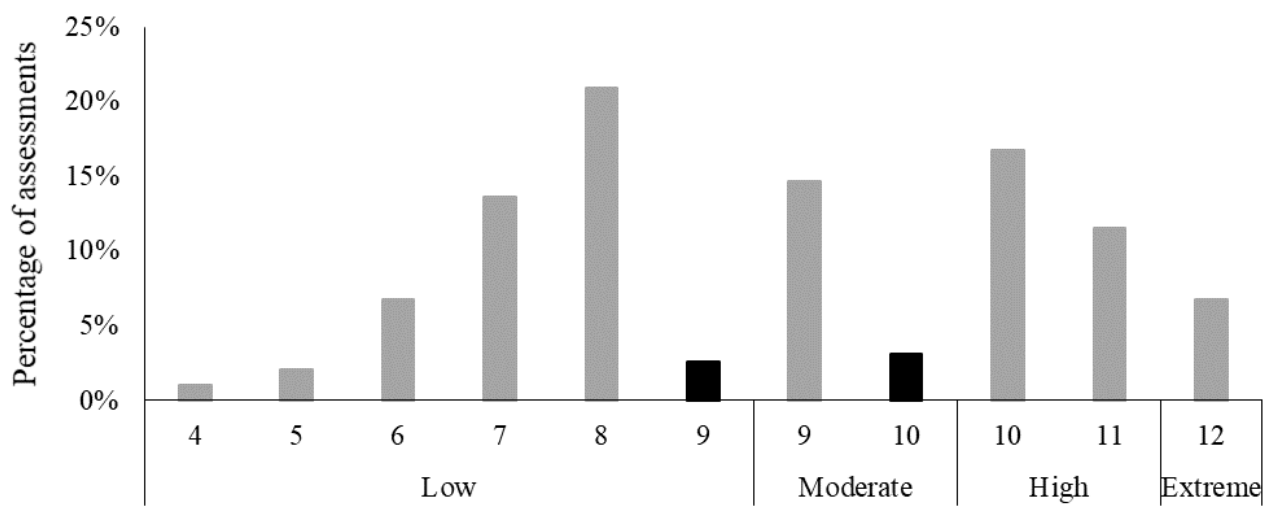

Semiquantitative and Qualitative Risk Rating

Figure 4. Distribution of risk rating for semiquantitative and qualitative analyses. Black bars represent assessments in the qualitative analysis (9 in "low" and 10 in "moderate").

Distribución de la clasificación del riesgo para los análisis cualitativo y semicuantitativo. Las barras negras representan evaluaciones en el análisis cualitativo ( 9 en "low" y 10 en "moderate"). 
(A)

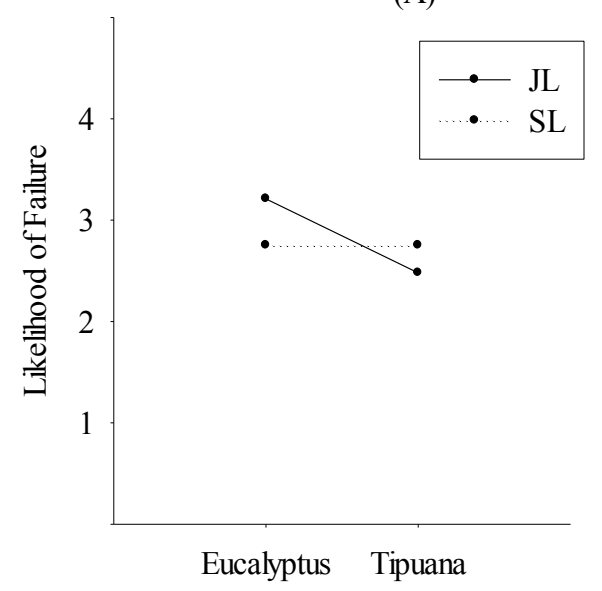

(C)

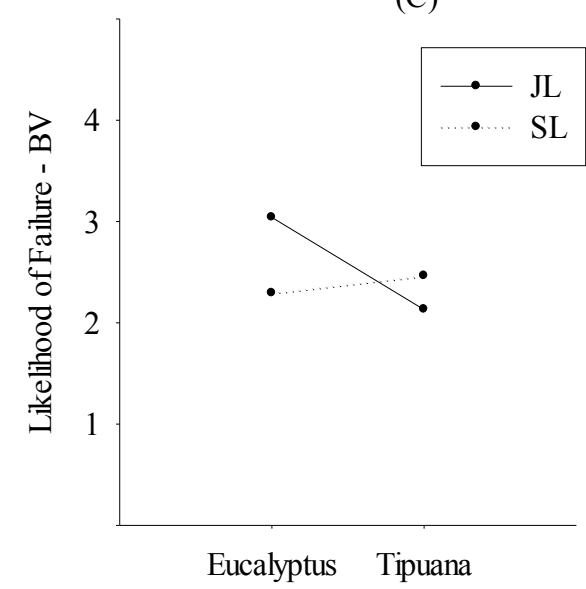

(B)

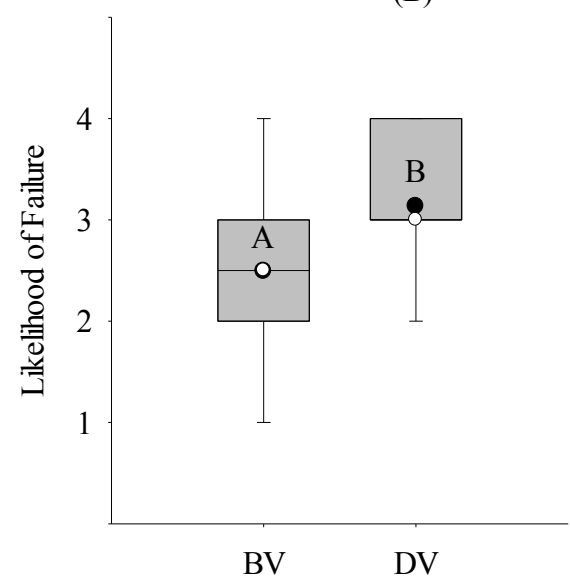

(D)

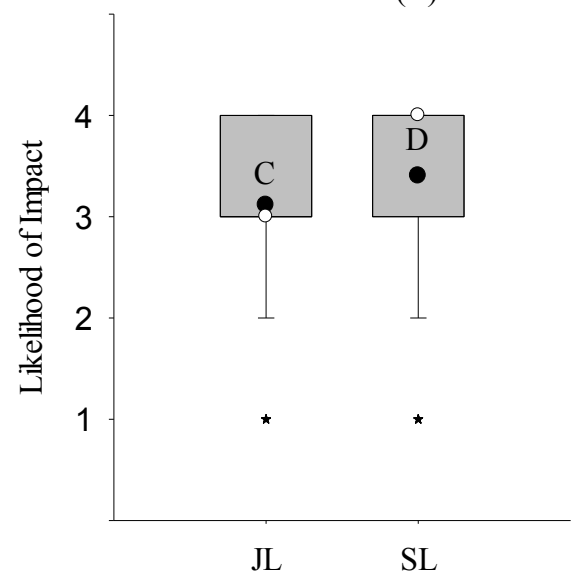

Figure 5. Scatter plot (mean and standard error) for (A) likelihood of failure $x$ Standardized Risk Rating for BV method, (B) likelihood of impact x Standardized Risk Rating for BV method, (C) consequence x Standardized Risk Rating for BV method, (D) likelihood of failure x Standardized Risk Rating for DV method, (E) likelihood of impact x Standardized Risk Rating for DV method, (F) consequence $\mathrm{x}$ Standardized Risk Rating for DV method. Dissimilar letters denote statistically significant differences in mean ratings as determined with an LSD Fisher test $(\alpha=0.01)$.

Diagrama de dispersión (media y error estándar) para (A) probabilidad de falla x clasificación del riesgo estandarizado para el método VB, (B) probabilidad de impacto $\mathrm{x}$ clasificación del riesgo estandarizado para el método $\mathrm{VB},(\mathrm{C})$ consecuencia $\mathrm{x}$ clasificación del riesgo estandarizado para el método $\mathrm{VB}$, ( D) probabilidad de falla x clasificación del riesgo estandarizado para el método VD, (E) probabilidad de impacto x clasificación del riesgo estandarizado para el método $\mathrm{VD},(\mathrm{F})$ consecuencia x clasificación del riesgo estandarizado para el método VD. Las letras diferentes denotan diferencias estadísticamente significativas en las medias determinadas con una prueba de LSD Fisher $(\alpha=0,01)$.

applying the DV method, the median would go from a low risk to a moderate one, contrasted with the BV method, although their values have been 8 and 9, respectively (figure $3 \mathrm{~A}$ ). When qualitatively analyzing the risk, the same situation occurs with the medians; however, in this case, there were no significant differences between the means (figure 3B). When risk ratings were compared, results showed that the qualitative analysis underestimated assessments by $6 \%$, when compared to the semiquantitative analysis (figure 4).

To calculate the risk rating of the BV method, the semiquantitative analysis proved to be the most appropriate, since it allowed visualizing the wide distribution of the risk assessments of trees (figure 3A), and it would avoid undervaluation. Being a proposed method that allows a first survey for risk management to be used at the time of inventorying trees, its rapid application due to the context of the Montevideo trees (Terrani 2014) provided an effective ranking of tree risk (Norris 2010, Koeser et al. 2016). In turn, the qualitative analysis was suitable for DV (figure 3B), since this method is mainly recommended for trees previously identified with high and extreme risk using the BV method. Since a numerical value as a final risk rating could lead to erroneous interpretations in this case, the use of the descriptors "low", "moderate", "high" and "extreme" is suggested (Koeser et al. 2016). Therefore, it 
is suggested to make an adequate description whether a number or an expression is used. As the DV method is proposed above all to confirm the highest risks, providing a higher level of information for decision making regarding the treatments necessary for risk mitigation, it is more efficient for municipality managers, considering the reduced number of trees in which its application would be necessary. A relevant aspect of this method is the ability to confirm most assessments obtained with the BV method; thus, $56 \%$ of the assessments carried out with the BV method classified in the standardized index 3 were confirmed as "high" with the DV method, while $41 \%$ were reclassified as "extreme" and $3 \%$ as "moderate". In turn, of the assessments with BV resulting in standardized index 4, 71 $\%$ were confirmed as "extreme" with DV and the rest were reclassified as "high". The above reaffirms the option of using both methods as a protocol.

Regarding the influence of the likelihood of failure, likelihood of impact and consequence on final risk rating, all of them had a significant effect (figure 5). However, the likelihood of failure was the component with the highest influence, since any increase in the valuation of said component significantly modified risk rating. In turn, a change in the valuation of the consequence from "insignificant" to "minor" and in the likelihood of impact from "very low" to "medium" meant no significant effect in the final risk rating (figure 5). In practice, this means that both methods and their respective proposed standardized risk rating systems were able to discriminate the situations where the utmost attention is required, that is, where there is most important exposure of the targets and superior potential damages (Ellison 2018). Finally, the larger effect of the likelihood of failure reinforces the recommendations of Koeser et al. (2015) regarding the need for the development of adequate guides and training adapted to the context for the evaluation of the attributes related to this likelihood.

\section{CONCLUSIONS}

The likelihood of failure was the only component that presented significant differences between the two proposed methods, with the assessment of branches being the attribute with the most important effect on the highest average resulting from the DV method.

The assessment of the likelihood of failure of the DV method, when assessing each part of the tree, reduced the effect of the type of assessor and the genus. The types of analyses used for the final risk rating behaved differently regarding distribution, where the semiquantitative analysis showed to be more suitable for the BV method, while the qualitative analysis was more suitable for DV.

Both methods were appropriate for the situations where they would be applied, since the BV method can be used during the execution of an inventory, establishing a ranking of the risk of a large number of trees. While for the specimens evaluated within standardized index 3 and 4 by the BV method (high and extreme, respectively) the DV method would be used to provide a better level of detail in the information.

The complementary application of BV and DV methods is recommended for the assessment of the risk of trees in urban parks of Montevideo under a risk management protocol, specially by municipalities and utility services.

\section{ACKNOWLEDGEMENTS}

We would like to thank all the professionals and students who participated in this work and the Montevideo municipality for the authorization and support to realize this work. This work was supported by Comisión Sectorial de Investigación Científica (CSIC), Universidad de la República (Uruguay).

\section{REFERENCES}

ANSI (American National Standards Institute, US). 2011. ANSI A300 (Part 9) - Tree Risk Assessment a. Tree Failure. 14 p.

Calaza P, MI Iglesias. 2016. El riesgo del arbolado urbano. Contexto, concepto y evolución. Madrid, España. Mundi-Prensa. $526 \mathrm{p}$.

Coelho-Duarte AP, G Daniluk-Mosquera, V Gravina, O Vallejos-Barra, M Ponce-Donoso. Tree Risk Assessment: component analysis of six visual methods applied in an urban park, Montevideo, Uruguay. Urban Forestry and Urban Greening 59:127005. DOI: https://doi.org/10.1016/j. ufug.2021.127005

Conceição I, R Samolão, A Santana. 2017. Proposal for a system of trees fall potential risk assessment in urban parks. Revista Árvore 41(4): 1-9. DOI: 10.1590/1806$\underline{90882017000400008}$

Di Rienzo JA, F Casanoves, MG Balzarini, L Gonzalez, M Tablada, CW Robledo. 2020. InfoStat versión 2020. Centro de Transferencia InfoStat, FCA, Universidad Nacional de Córdoba, Argentina. Consulted 27 mar. 2020. Available in www.infostat.com.ar

Dunster JA, ET Smiley, N Matheny, S Lilly. 2017. Tree Risk Assessment Manual. 2nd ed. Champaign, United States. International Society of Arboriculture. $194 \mathrm{p}$.

Ellison M. 2018. Nota de procedimiento Quantified Tree Risk Assessment Version 5. Cheshire, United Kingdom. Quantified Tree Risk Assessment Limited. 9 p.

Forbes-Laird J. 2010. THREATS - Tree Hazard Risk Evaluation and Treatment System - Guidance note for users. Forbes-Laird Arboricultural Consultancy. Consulted 27 mar. 2020. Available in www.flac.uk.com/wp-content/ uploads/2010/07/THREATS-GN-June-2010.pdf

Guyon J, C Cleaver, M Jackson, A Saavedra, P Zambino. 2017. A Guide to Identifying, Assessing, and Managing Hazard Trees in Developed Recreational Sites of the Northern Rocky Mountains and the Intermountain West. USDA Forest Service, Northern and Intermountain Regions. Consulted 31 mar. 2020. Available in https://www.fs.usda.gov/Internet/FSE DOCUMENTS/fseprd571021.pdf

INUMET (Instituto Uruguayo de Meteorología, UY). 2020. Estadísticas climatológicas. Consulted 31 ago. 2020. Availa- 
ble in https://www.inumet.gub.uy/index.php/clima/estadis$\underline{\text { ticas-climatologicas }}$

Ivasko J, D Biondi, E Ximenes, A Nunho, B Heck. 2019. Risk assessment of trees protected by law in Curitiba squares, Paraná, Brazil. Bosque 40(3): 347-354. DOI: $10.4067 /$ $\underline{\mathrm{s} 0717-92002019000300347}$

Koeser AK, G Hasing, D McLean, R Northrop. 2016. Tree Risk Assessment Methods: A Comparison of Three Common Evaluation Forms. Consulted 31 ago. 2020. Available in https://edis.ifas.ufl.edu/ep487

Koeser AK, RW Klein, G Hasing, RJ Northrop. 2015. Factors driving professional and public urban tree risk perception. Urban Forestry \& Urban Greening 14(4): 968-974. DOI: https://doi.org/10.1016/j.ufug.2015.09.004

Koeser AK, RJ Hauer, RW Klein, JW Miesbauer. 2017. Assessment of likelihood of failure using limited visual, basic, and advances assessment techniques. Urban Forestry \& Urban Greening 24: 71-79. DOI: https://doi. org/10.1016/j.ufug.2017.03.024

Koeser AK, ET Smiley. 2017. Impact of assessor on tree risk assessment ratings and prescribed mitigation measures. Urban Forestry \& Urban Greening 24: 109-115. DOI: https://doi.org/10.1016/j.ufug.2017.03.027

Matheny NP, JR Clark. 1994. A Photographic Guide to the Evaluation of Hazard Trees in Urban Areas. Champaign, United States. International Society of Arboriculture. 85 p.

Norris M. 2010. A Review of Methods Used to Undertake Risk Assessments of Urban Trees. MSc. Thesis. Melbourne, Australia. School of Resource Management. University of Melbourne. 398 p.

Pokorny JD. 2003. Urban Tree Risk Management: A Community Guide to Program Design and Implementation. USDA
Forest Service, Northeastern Area, State and Private Forestry. Consulted 30 mar. 2020. Available in https://www. fs.usda.gov/naspf/publications/urban-tree-risk-management-community-guide-program-design-and-implementation

Ponce-Donoso M, O Vallejos-Barra, G Daniluk-Mosquera. 2012. Comparación de fórmulas chilenas e internacionales para valorar el arbolado urbano. Bosque 33(1): 69 - 81 . DOI: https://doi.org/10.4067/S0717-92002012000100008

Ponce-Donoso M, O Vallejos-Barra. 2016. Valoración de árboles urbanos, comparación de fórmulas. Revista de la Facultad de Ciencias Agrarias de la Universidad Nacional de Cuyo 48(2): 195-208.

Reyes de la Barra J, M Ponce-Donoso, O Vallejos-Barra, G Daniluk-Mosquera, AP Coelho-Duarte. 2018. Comparación de cuatro métodos de evaluación visual del riesgo de árboles urbanos. Colombia Forestal 21(2): 161-173. DOI: 10.14483/2256201X.12604

Rooney CJ, HDP Ryan, DV Bloniarz, BCP Kane. 2005. The reliability of a windshield survey to locate hazards in roadside trees. Journal of Arboriculture 31(2): 89-94.

Sampaio ACF, FG Duarte, EGC Silva, BLD De Angelis, CT Blum. 2010. Avaliação de árvores de risco na arborização de vias públicas de Nova Olímpia, Paraná. Revista da Sociedade Brasileira de Arborização Urbana 5(2): 82-104. DOI: http://dx.doi.org/10.5380/revsbau.v5i2.66278

Terrani E. 2014. Evaluación de la estructura y comportamiento del arbolado urbano en Montevideo. Tesis Ingeniero Agrónomo. Montevideo, Uruguay. Facultad de Agronomía, Universidad de la República. 112 p.

Wessoly L, M Erb. 2016. Manual of tree statics and tree inspection. Berlin-Hanover, Germany. Platzer-Verlag. 288 p. 